\title{
Markov Chain: A Predictive Model for Manpower Planning
}

\author{
${ }^{* 1}$ EZUGWU, VO; ${ }^{2}$ OLOGUN, $\mathrm{S}$ \\ ${ }^{1,2}$ Department of Mathematics and statistics \\ University of Uyo, Akwa-Ibom State, Nigeria \\ ezugwuvitus@gmail.com,2.osipmaths@yahoo.com
}

\begin{abstract}
The use of Mathematical models for manpower planning has increased in recent times for better manpower planning quantitatively. In respect of organizational management, numerous previous studies have applied Markov chain models in describing title or level promotions, demotions, recruitments, withdrawals, or changes of different career development paths to confirm the actual manpower needs of an organization or predict the future manpower needs. The movements of staff called transitions are usually the consequences of promotions, transfer between segments or wastage and recruitment into the system. The objective of the study is to determine the proportions of staff recruited, promoted and withdrawn from the various grades and to forecast the academic staff structure of the university in the next five years. In this paper, we studied the academic staff structure of university of Uyo, Nigeria using Markov chain models. The results showed that there is a steady increase in the number of Graduate Assistants, Senior Lecturer and Associate professors, while, there is a steady decrease in the number of Assistant Lecturer, Lecturer II, Lecturer I, and Professor in the next five years. The model so developed can only be applied when there is no control on recruitment but the research can be extended to include control on recruitment. The model can also be applied in school enrollment projection. CJASEM
\end{abstract}

\section{https://dx.doi.org/10.4314/jasem.v21i3.17}

Keywords: Markov Chain, Transition Probability Matrix, Manpower Planning, Recruitment, Promotion, Wastage.

A Markov chain (Discrete Time Markov Chain, DTMC), named after a Russian Mathematician, Andrey Markov in 1907, is a random process that undergoes transition from one state to another on a state space. Markov process is a synthesis of movements between states to describe the relocations of members of the transfer probability matrix to different states, on the basis of the mobility trend of historical data, Meng-Chuan et al, (2014). In the respect of organizational management, numerous previous studies have applied the Markov chain in describing title or level promotions, demotions, or changes of different career development paths to confirm the actual manpower needs of an organization or predict the future manpower needs. Optimization of manpower and forecasting manpower needs in modern conglomerates are essential part of the future strategic planning and a very important different nature of business imperatives, (Adisak, 2015). The Markov chain model allows us to answer questions from policy makers. For example, it allows easy computation of various statistics at both individual and aggregate levels. At the individual level, it can be used to describe the probabilistic progression for a staff at a given career stage. At aggregate level, it can be used to derive information on overall continuation rates and separation behavior which are critical inputs in developing retention programs. Markov chain model has been widely used in different fields including Education to study students' enrolment projection both in secondary schools and tertiary institutions. Education system is comparable to a hierarchal organization in which after an academic session, three possibilities arise in the new status of the students; the students may move to the next higher class, may repeat the same class, or leave the system successfully as graduates or drop out of the system before attaining the maximum qualification

(Nyandwaki and Kennedy, 2016). Modeling the manpower management mainly concerns the prediction of future behavior of employees, (Rachid and Mohamed, 2013). Trend researchers used Markov chain model associated or integrated to describe the change of the process in light of its historical evolutions, (Bartholomew, 1991).

Markov chain is one of the techniques used in operations research with possibilities view that managers in organizational decision making bodies use, Hamedet at, (2013). Manpower planning is the process by which the management determines how an 
organization should move from its current manpower position to its desired manpower position. Through planning, management strives to have the right number and right kinds of people, at the right places at the right time, doing things which result in both the organization and individual receiving maximum long-run benefits. Collings and Wood (2009) defined manpower planning as the range of philosophies, tools and techniques that any organization should deploy to monitor and manage the movement of staff both in terms of numbers and profiles. These movements of staff called transitions are usually the consequences of promotions, transfer between segments or wastage and recruitment into the system. The approach to manpower policy in most Nigerian universities appears to be guided by the traditional method of putting the right number of people in the right place at the right time or arranging the suitable number of people to be allocated to various jobs usually in a hierarchal structure, (Igboanugo and Onifade, 2011). Manpower planning involves two stages. The first stage is concerned with the detailed planning of manpower requirements for all types and levels of employees throughout the planning period and the second stage is concerned with the planning of manpower supplies to provide the organization with the right types of people from all sources to meet the planning requirements. An adage says, he who fails to plan, plans to fail. The planning process is one of the most crucial, complex and continuing managerial functions which embraces organizational development, managerial development, career planning and succession planning. The process of manpower planning may rightly be regarded as a multi-step process including various issues such as ; Deciding goals or objectives, Auditing of internal resources, Formulation of recruitment plan, Estimating future organizational structure and manpower requirements and developing a human resource plan. Effective manpower planning is very crucial which organizations, like large companies, academic system, federal and state administration must carryout, since human resources are considered as the most crucial, volatile and potentially unpredicted resource which an organization utilizes. The prediction of manpower is subject to how current supply of employees will change internally. These changes are observed by analyzing what happened in the past, in terms of staff retention or movement, extrapolating into the future to see what happens with the same trend of the past.

Markov chain is a useful tool in prediction and has been used extensively in many areas of human endeavors. Rachid and Mohamed (2013) presented a predictive model of numbers of employees in a hierarchal dependent- time system of human resources, incorporating subsystems that each contains grades of the same family. The proposed model was motivated by the reality of staff development which confirms that the path evolution of each employee is usually in its family of grades. Kwon et at, (2006) used Marko chain model and job coefficient to investigate the difference of manpower status between US and Korean nuclear industry and to predict the future manpower requirements in Korea. The workforce planning, on the basis of established process, requires a good knowledge of those deployed in the establishment, as well as entry, dropout ant promotion of employees in order to reach a future plan fit and desired administration in determining the future policies of the workforce system, Touama, (2015) applied Markovian models and transition probability matrix to analyze the movement of the workforce in Jordan productivity companies. To achieve his aim, he collected secondary data related to workforce movement selected from annual reports of Jordanian productivity companies (potash, phosphate and pharmaceutical) for year 2004. The purpose of manpower planning is to get a better matching between manpower requirements and manpower availability. Parma et al, (2013) considered an optimization model for manpower system where vacancies are filled up by promotion and recruitment in automation system engineering private limited. They proposed a method for the determination of transition probability of promotion and recruitment vector by using Markovian theory with certain assumptions. The approach to manpower planning in Nigerian universities are guided by the traditional method of putting the right number of people in the right place at the right time or arranging a suitable number of people to be allocated to various jobs usually in a hierarchal structure. However, this method is difficult in that it does not offer computational tools that will enable administrators to determine possible line of action to be taken nor provides tools to generate alternative policies and strategies. Rahela, (2015) analyzed manpower data of higher learning institution using Markov chain. His objective was to design a planning model for projecting university faculty employment under alternative policies suggested by the government. Wan-yin and Shou, (2015) focused on the improved gray Markov model in human resource internal supply forecasting, so that enterprises can reasonably predict their internal human resource supply through Markov model and provide important guarantee for enterprises to develop human resources strategic planning. Ekhosuehi, (2013) examined the passage of staff in a faculty using one state absorbing Markov 
chain. He considered two cases involving regardless of staff leaving intension and staff unwillingness to leave. Babu and Rao, (2013) carried out studies on two graded manpower model with bulk recruitment in both grades. They assumed that the organization is having two grades and recruitment is done in both grades in bulk. Osagiede and Ekhosuehi, (2006) presented the use of Markovian model to project the future enrolment of students in a university where they removed the assumption of certain constant values in the rate of new intake by some previous authors and provided a better method for calculating the constant value of increment in the new intake. The objective of this study is to determine the proportions of staff recruited, promoted and withdrawn from the various grades and to forecast the academic staff structure of the university in the next five years.

\section{MATERIALS AND METHODS}

Description of Study Area: In this paper, the academic staff manpower system of university of
Uyo is modeled using Markov chain predictive model. The objective of the study is to determine the proportion of staff promoted, withdrawn, and recruited into the various grades, and to predict the manpower structure of the University of Uyo for several years to come if the policy of recruitment and promotion remain unchanged. In the university, vacancies are filled by promotion from the serving staff or by recruitment from outside the system. Promotion is done every year and each staff is promoted every three years after meeting the requirements for promotion, otherwise, no promotion for that particular staff. In the university, we have categories of academic staff. They are; Graduate Assistant (GA), Assistant Lecturer (AL), Lecture II (LII), Lecturer I (LI), Senior Lecturer (SL), Associate Professor (AP), Professor (P). These grades form the states of the system. These states are mutually exclusive and collectively exhaustive. Each member of staff transitions from one grade to the next higher grade.

Here, we use first order time-independent homogeneous Markov chain. A Markov chain is a sequence of random variables $X_{1}, X_{2}, X_{3}, \ldots$ with the Markov property, namely that the probability of moving to next state depends entirely on the present state, not on the previous states. ie

$$
p\left\lfloor X_{n+1}=j / X_{1}, X_{2}, \ldots, X_{n}\right\rfloor=P\left\lfloor X_{n+1}=j / X_{n}=i\right\rfloor, \forall i, j
$$

The basic manpower model is of the form

$n_{j}(t+1)=\sum_{i=1}^{k} n_{i}(t) p_{i j}(t)+R_{j}(t), \forall i, j=1,2, \ldots, k \ldots .(2)$

Equation (2) can be expressed as

$n_{j}(t+1)=n_{i}(t) p_{i i}(t)+n_{i}(t) p_{i j}(t)+R_{j}(t) \ldots . .(3)$

This gives the number of staff in grade $j$ at time $t+1$. Then the total number of staff in the system at time

$t+1$ is $n(t+1)=\sum_{j=1}^{k} n_{j}(t+1)=\sum_{j=1}^{k} \sum_{i=1}^{k} n_{i}(t) p_{i j}(t)+\sum_{j=1}^{k} \boldsymbol{R}_{j}$

NOTATIONS AND THEIR MEANINGS

$t=1,2, \ldots, T$; Planning periods, with $T$ being the horizon, the value of $t$ represents a session

$i=1,2, \ldots, k$; The states of the system which represent the various grades of academic staff in the university.

These states are mutually exclusive and collectively exhaustive

$n_{i j}(t)$; The number of academic staff (promotion flow) who transition from grade $i$ to $j$ at the th session

$\boldsymbol{n}_{i}(t)$; The number of staff in grade $i$ at the beginning of $t$ th session

$\boldsymbol{R}_{j}(t)$; The number of recruits into grade $j$ at the beginning of $t$ th session

$W_{i}(t)$; Wastage from grade $i$

$P_{i j}(t)$; The probability of a staff moving from grade $i$ to grade $j$ at the beginning of $t$ th session 
$p_{i 0}(t)$; The probability of staff in grade $i$ leaving the system at the $t$ th session

$p_{0 j}(t)$; The probability of recruitment into grade $j$ at the beginning of $t$ th session

Where 0 is a state outside the system.

ASSUMPTIONS OF THE MODEL

These are the assumptions of the model;

1. There are seven grades of academic staff in the system

2. Promotion is done every year and every staff is promoted every three years after obtaining the required number of publications, otherwise there is no promotion for that particular staff.

3. There is no double promotion and no demotion, ie $p_{i j}(t)=0, \forall j \succ i+1$ and $j \leq i-1$

4. The probability of withdrawal of staff and probability of recruitment of new staff are independent with probabilities $p_{i 0}$ and $p_{0 j}, \forall i, j=1,2, \ldots, k$ respectively. That is the probability that staff who leave the system in grade $i$ will be replaced by recruit who enter the system in grade $j$, ie $p_{i j}=\left(p_{i 0}\right)\left(p_{0 j}\right)$

5. There is recruitment in all the grades $j=1,2, \ldots, k$ such that $\sum_{j=1}^{k} p_{0 j}=1$

6. The transition probability matrix (TPM) is stationary overtime. The transition probability matrix is gives as

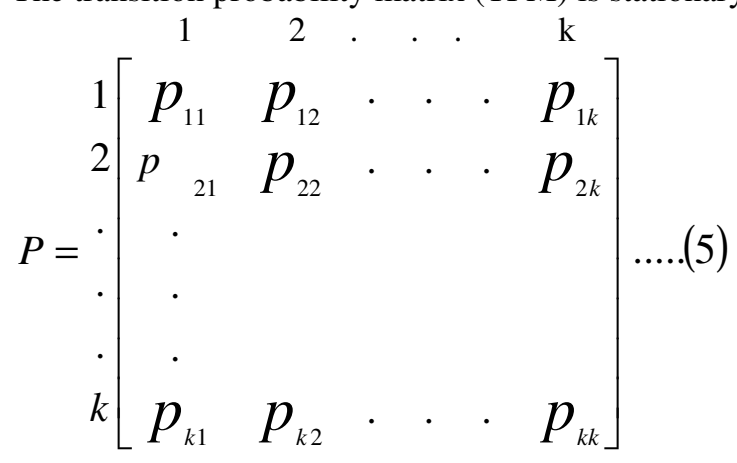

Such that $\sum_{i=1}^{k} p_{i j}=1-W_{i}$. This means that $P$ is a sub-matrix.

\section{ESTIMATION OF TRANSITION PROBABILITY MATRIX}

Let $\boldsymbol{n}_{i j}(t)$ be the flow level from grade $i$ to $j$ during the $t$ th period. Then, the distribution is multinomial with probabilities $p_{i j}(t), \forall i, j=1,2, \ldots, k$ (Uche and Ezepue, 1991). The distribution is given as $p\left[n_{i 1}(t), n_{i 2}(t), \ldots, n_{i k}(t)\right]=\frac{\left(\sum_{i=1}^{k} n_{i j}(t)\right) !}{\prod_{i=1}^{k}\left(n_{i j}(t)\right) !} \prod_{i=1}^{k} p_{i j}^{n_{i j}(t)}$

The likelihood function given by (lindgreen, 1993) is

$$
\hat{p}_{i j}(t)=\frac{n_{i j}(t)}{n_{i}(t)}, \forall i, j=1,2, \ldots, k \text { and } \forall t=1,2, \ldots, T
$$

Since we assume that the transition probability matrix is stationary over time, the maximum likelihood estimates of $\hat{p_{i j}}(t)$ is calculated by pooling equation $(7)$, that is 
$\hat{p_{i j}}(t)=\frac{\sum_{t=1}^{T} n_{i j}(t)}{\sum_{i=1}^{T} n_{i}(t)}$

PREDICTIVE MODEL FOR FUTURE ACADEMIC STAFF STRUCTURE

Let $\hat{n}(t)$ be a row vector of grade sizes at the beginning of the $t$ th session, that is

$\underset{\boldsymbol{n}}{\hat{(}(t)}=\left[\hat{\boldsymbol{n}_{1}}(t), \hat{n}_{2}(t), \ldots, \boldsymbol{n}_{k}(t)\right]$ where, the cap and bottom bar indicate the expected and vector respectively.

Then $\underset{=}{n}(t+1)=\stackrel{\wedge}{n}(t) Q$

where

$\hat{n}(t+1)=\left[n_{1}(t+1), n_{2}(t+1), \ldots . \cdot n_{k}(t+1)\right]$

and

\begin{tabular}{|c|c|c|c|c|c|c|}
\hline 1 & 2 & 3 & 4 & 5 & 6 & 7 \\
\hline$p_{11}+p_{10} p_{01}$ & $p_{12}+p_{10} p_{02}$ & 0 & 0 & 0 & 0 & 0 \\
\hline $2 \quad p_{20} p_{01}$ & $p_{22}+p_{20} p_{02}$ & $p_{23}+p_{20} p_{03}$ & 0 & 0 & 0 & 0 \\
\hline$p_{30} p_{01}$ & $p_{30} p_{02}$ & $p_{33}+p_{30} p_{03}$ & $p_{34}+p_{30} p_{04}$ & 0 & 0 & 0 \\
\hline$p_{40} p_{01}$ & $p_{40} p_{02}$ & $p_{40} p_{03}$ & $p_{44}+p_{40} p_{04}$ & $p_{45}+p_{40} p_{05}$ & 0 & 0 \\
\hline$p_{50} p_{01}$ & $p_{50} p_{02}$ & $p_{50} p_{03}$ & $p_{50} p_{04}$ & $p_{55}+p_{50} p_{05}$ & $p_{56}+p_{50} p_{06}$ & 0 \\
\hline$p_{60} p_{01}$ & $p_{60} p_{02}$ & $p_{60} p_{03}$ & $p_{60} p_{04}$ & $p_{60} p_{05}$ & $p_{66}+p_{60} p_{06}$ & $p_{67}+p_{60} p_{07}$ \\
\hline$p_{70} p_{01}$ & $p_{70} p_{02}$ & $p_{70} p_{03}$ & $p_{70} p_{04}$ & $p_{70} p_{95}$ & $p_{70} p_{06}$ & $p_{77}+p_{70} p_{07}$ \\
\hline
\end{tabular}

since $p_{i j}=\left(p_{i 0}\right)\left(p_{0 j}\right)$

In order to obtain the parameters of the model, secondary data for academic staff flow (promotions) in the university of uyo, Nigeria for the periods between 2011/2012 and 2014/2015 were collected. The data are presented in the tables below.

DATA; the tables below are the data for academic staff flow based on recruitment, promotion and wastage for each session under study. 
Table 1; Academic staff flow based on recruitment, promotion and wastage for 2011/2012 session

\begin{tabular}{lllllllllll}
\hline & $\mathbf{1}$ & $\mathbf{2}$ & $\mathbf{3}$ & $\mathbf{4}$ & $\mathbf{5}$ & $\mathbf{6}$ & $\mathbf{7}$ & $\boldsymbol{W}_{i}$ & $\boldsymbol{n}_{i}(t)$ \\
\hline $\mathbf{1}$ & 102 & 0 & 0 & 0 & 0 & 0 & 0 & 0 & 102 \\
$\mathbf{2}$ & 0 & 189 & 5 & 0 & 0 & 0 & 0 & 1 & 195 \\
$\mathbf{3}$ & 0 & 0 & 276 & 6 & 0 & 0 & 0 & 4 & 286 \\
$\mathbf{4}$ & 0 & 0 & 0 & 269 & 17 & 0 & 0 & 3 & 289 \\
$\mathbf{5}$ & 0 & 0 & 0 & 0 & 279 & 10 & 0 & 1 & 290 \\
$\mathbf{6}$ & 0 & 0 & 0 & 0 & 0 & 101 & 5 & 4 & 110 \\
$\mathbf{7}$ & 0 & 0 & 0 & 0 & 0 & 0 & 233 & 8 & 241 \\
$\boldsymbol{R}_{j}$ & 22 & 21 & 57 & 30 & 15 & 0 & 1 & & \\
\hline
\end{tabular}

Table 2; Academic staff flow based on recruitment, promotion and wastage for 2012/2013

\begin{tabular}{llllllllll}
\hline & $\mathbf{1}$ & $\mathbf{2}$ & $\mathbf{3}$ & $\mathbf{4}$ & $\mathbf{5}$ & $\mathbf{6}$ & $\mathbf{7}$ & $\boldsymbol{W}_{i}$ & $\boldsymbol{n}_{i}(t)$ \\
\hline $\mathbf{1}$ & 88 & 1 & 0 & 0 & 0 & 0 & 0 & 2 & 91 \\
$\mathbf{2}$ & 0 & 170 & 10 & 0 & 0 & 0 & 0 & 2 & 182 \\
$\mathbf{3}$ & 0 & 0 & 221 & 12 & 0 & 0 & 0 & 4 & 237 \\
$\mathbf{4}$ & 0 & 0 & 0 & 311 & 14 & 0 & 0 & 1 & 326 \\
$\mathbf{5}$ & 0 & 0 & 0 & 0 & 264 & 7 & 0 & 3 & 274 \\
$\mathbf{6}$ & 0 & 0 & 0 & 0 & 0 & 95 & 2 & 2 & 99 \\
$\mathbf{7}$ & 0 & 0 & 0 & 0 & 0 & 0 & 201 & 3 & 204 \\
$\boldsymbol{R}_{j}$ & 12 & 15 & 12 & 5 & 2 & 1 & 0 & & 52 \\
\hline
\end{tabular}

Table 3; Academic staff flow based on recruitment, promotion and wastage for 2013/2014

\begin{tabular}{llllllllll}
\hline & $\mathbf{1}$ & $\mathbf{2}$ & $\mathbf{3}$ & $\mathbf{4}$ & $\mathbf{5}$ & $\mathbf{6}$ & $\mathbf{7}$ & $\boldsymbol{W}_{i}$ & $\boldsymbol{n}_{i}(t)$ \\
\hline $\mathbf{1}$ & 117 & 0 & 0 & 0 & 0 & 0 & 0 & 2 & 119 \\
$\mathbf{2}$ & 0 & 177 & 9 & 0 & 0 & 0 & 0 & 2 & 188 \\
$\mathbf{3}$ & 0 & 0 & 251 & 15 & 0 & 0 & 0 & 6 & 272 \\
$\mathbf{4}$ & 0 & 0 & 0 & 292 & 25 & 0 & 0 & 3 & 320 \\
$\mathbf{5}$ & 0 & 0 & 0 & 0 & 326 & 9 & 0 & 0 & 335 \\
$\mathbf{6}$ & 0 & 0 & 0 & 0 & 0 & 125 & 2 & 2 & 129 \\
$\mathbf{7}$ & 0 & 0 & 0 & 0 & 0 & 0 & 200 & 4 & 204 \\
$\boldsymbol{R}_{j}$ & 41 & 55 & 21 & 10 & 8 & 3 & 2 & & 140 \\
\hline
\end{tabular}

Table 4; Academic staff flow based on recruitment, promotion and wastage for 2014/2015

\begin{tabular}{llllllllll}
\hline & $\mathbf{1}$ & $\mathbf{2}$ & $\mathbf{3}$ & $\mathbf{4}$ & $\mathbf{5}$ & $\mathbf{6}$ & $\mathbf{7}$ & $\boldsymbol{W}_{i}$ & $\boldsymbol{n}_{i}(t)$ \\
\hline $\mathbf{1}$ & 94 & 3 & 0 & 0 & 0 & 0 & 0 & 1 & 98 \\
$\mathbf{2}$ & 0 & 152 & 13 & 0 & 0 & 0 & 0 & 1 & 166 \\
$\mathbf{3}$ & 0 & 0 & 242 & 9 & 0 & 0 & 0 & 4 & 255 \\
$\mathbf{4}$ & 0 & 0 & 0 & 266 & 21 & 0 & 0 & 0 & 287 \\
$\mathbf{5}$ & 0 & 0 & 0 & 0 & 353 & 12 & 0 & 4 & 269 \\
$\mathbf{6}$ & 0 & 0 & 0 & 0 & 0 & 111 & 4 & 1 & 116 \\
$\mathbf{7}$ & 0 & 0 & 0 & 0 & 0 & 0 & 210 & 3 & 213 \\
$\boldsymbol{R}_{j}$ & 1 & 1 & 4 & 2 & 2 & 1 & 0 & & 11 \\
\hline
\end{tabular}


Table 5: Pooled academic staff flow based on recruitment, promotion and wastage for all the sessions

\begin{tabular}{llllllllll}
\hline & $\mathbf{1}$ & $\mathbf{2}$ & $\mathbf{3}$ & $\mathbf{4}$ & $\mathbf{5}$ & $\mathbf{6}$ & $\mathbf{7}$ & $\boldsymbol{W}_{i}$ & $\boldsymbol{n}_{i}(t)$ \\
\hline $\mathbf{1}$ & 401 & 4 & 0 & 0 & 0 & 0 & 0 & 5 & 410 \\
$\mathbf{2}$ & 0 & 688 & 37 & 0 & 0 & 0 & 0 & 6 & 731 \\
$\mathbf{3}$ & 0 & 0 & 990 & 43 & 0 & 0 & 0 & 18 & 1050 \\
$\mathbf{4}$ & 0 & 0 & 0 & 1138 & 77 & 0 & 0 & 7 & 1222 \\
$\mathbf{5}$ & 0 & 0 & 0 & 0 & 1222 & 38 & 0 & 8 & 1265 \\
$\mathbf{6}$ & 0 & 0 & 0 & 0 & 0 & 432 & 13 & 9 & 454 \\
$\mathbf{7}$ & 0 & 0 & 0 & 0 & 0 & 0 & 844 & 18 & 862 \\
$\boldsymbol{R}_{j}$ & 76 & 92 & 94 & 47 & 27 & 5 & 3 & & 344 \\
\hline
\end{tabular}

\section{RESULTS AND DICUSSIONS}

From the pooled academic staff flow based on recruitment, promotion and withdrawal, the transition probability matrix $P$, the wastage probabilities $p_{i 0}$, and the recruitment probabilities $p_{0 j}$ are obtained using equation (8) as follows,

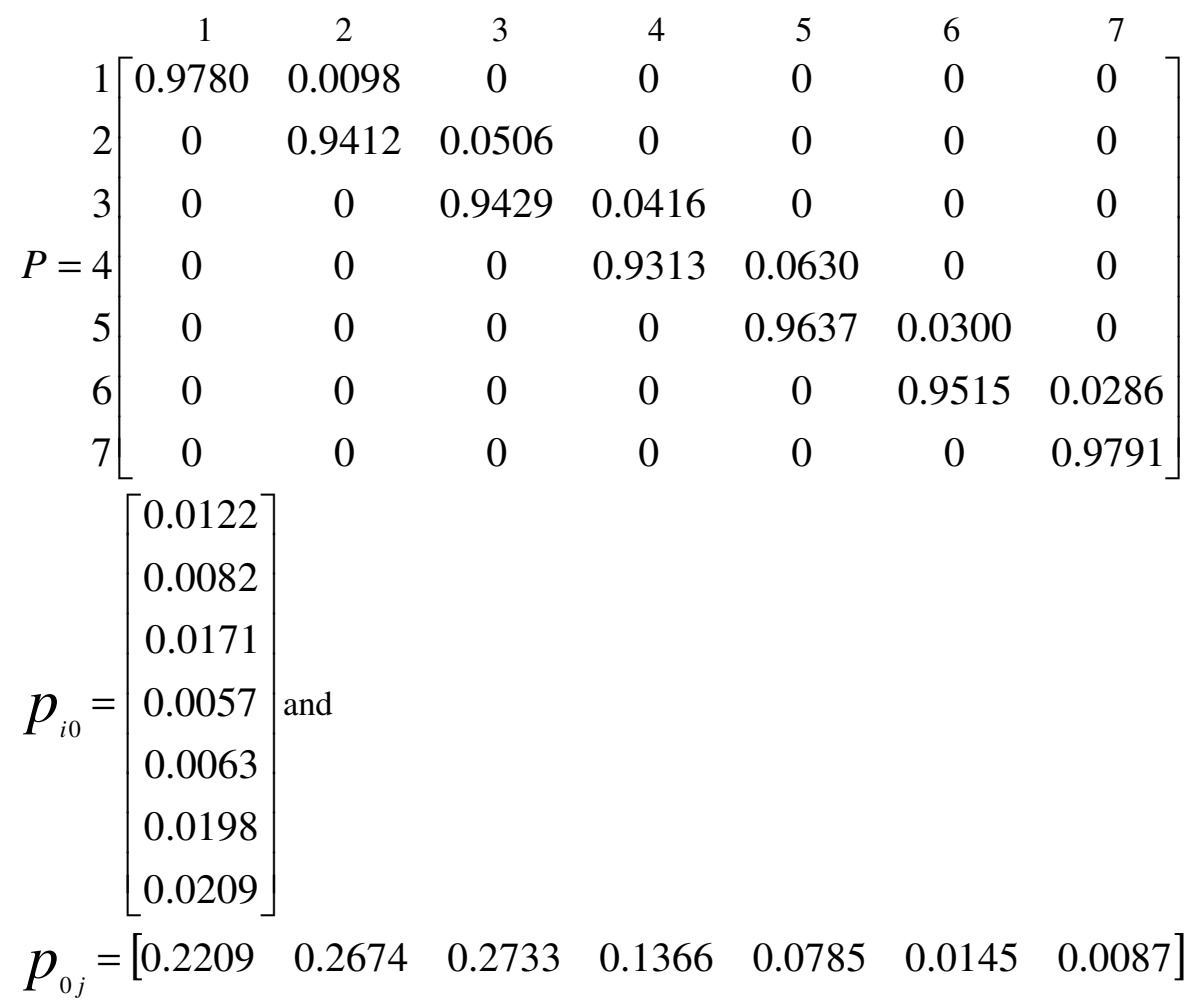

Using the transition probability matrix $P$, the wastage probability $p_{i 0}$ and the recruitment probability $p_{0 j}$ the matrix $Q$ is obtained as 


$$
Q=\left[\begin{array}{ccccccc}
0.9807 & 0.0131 & 0 & 0 & 0 & 0 & 0 \\
0.0018 & 0.9434 & 0.0528 & 0 & 0 & 0 & 0 \\
0.0038 & 0.0047 & 0.9476 & 0.0439 & 0 & 0 & 0 \\
0.0013 & 0.0015 & 0.0016 & 0.9321 & 0.0634 & 0 & 0 \\
0.0014 & 0.0017 & 0.0017 & 0.0009 & 0.9637 & 0.0301 & 0 \\
0.0042 & 0.0053 & 0.0054 & 0.0027 & 0.0016 & 0.9518 & 0.0288 \\
0.0046 & 0.0056 & 0.0057 & 0.0029 & 0.0016 & 0.0003 & 0.9793
\end{array}\right]
$$

Using equation $(9)$, the predicted academic staff structure for the next five years if the policy for promotion and recruitment remained unchanged is given in the table below.

Table 6: The predicted academic staff structure for university of Uyo in the next five sessions

\begin{tabular}{llllllllll}
\hline SESSION & 1 & 2 & 3 & 4 & 5 & 6 & 7 & $n(t)$ \\
\hline $2015 / 2016$ & 99 & 176 & 250 & 284 & 371 & 121 & 209 & 1510 \\
$2016 / 2017$ & 101 & 171 & 247 & 276 & 376 & 126 & 208 & 1505 \\
$2017 / 2018$ & 103 & 166 & 255 & 269 & 381 & 131 & 207 & 1512 \\
$2018 / 2019$ & 105 & 162 & 254 & 263 & 385 & 136 & 206 & 1511 \\
$2019 / 2020$ & 107 & 158 & 252 & 258 & 388 & 141 & 206 & 1510 \\
\hline
\end{tabular}

The results indicate that grade 7 (professor) has the highest wastage probability. This could be attributed to their age and closeness to retirement, while grades 2 and 3 (Assistant Lecturer and Lecturer II) have the highest recruitment probability.

In matrix $Q$, the entries in columns $1-6$ of each transition matrix arise from replacement matrix and recruitment policy of the university as new entrants are recruited into all the grades. That is, in the columns, the entry is the probability that a staff, either repeated grade $i$, is promoted from grade $i$ to $j$ or the staff is recruited into $j$ to replace the leavers in grade $i$. The zero entries indicate that there is no transition between the corresponding years of promotion. The major diagonal elements (repetition probabilities) of matrices $P$ and $Q$ are relatively large, while, the upper off-diagonal elements (promotion probabilities) are relatively small. This means that on average, an insignificant number of staff in each grade is being promoted every year. The reason could be that most of the academic staff are not actively involved in research to meet with the conditions for promotion or the management of the university is not much interested in promotion of staff and this condition will not augur well with the staff in particular and the system in general.

Conclusion: The prediction made in this research has shown that, there is a steady increase in the number of Graduate Assistants, Senior Lecturer and Associate professors, while, there is a steady decrease in the number of Assistant Lecturer, Lecturer II, Lecturer I, and Professor in the next five years. However, the system may grow out of proportion if there is no control on recruitment. This research can be extended to include recruitment control by placing control on recruitment. A model for this can be developed.

\section{REFERENCES}

Adisak, C (2015). The Development of Manpower Modeling and Optimization: A Case Study of Asia Leading Energy Conglomerates. Global Journal of Human Resource Management. 3(2): $34-57$.

Babu, PK;Rao, KS (2013).Studies on Two Graded Manpower Model with Bulk Recruitment in Both Grades. International Journal on Human Resource Management Research, 1(2); 10 - 51

Bartholomew, DJ; Forbes, AF; McClean, SI (1991). Statistical Techniques for Manpower Planning $\left(2^{\text {nd }}\right.$ ed.). John Willy \& Sons, Chichester.

Collings, DG; Wood, G (2009). Human Resources Management; A Critical Approach. Routledge, London

Ekhosuehi, VU (2013). Evolution of Career Patterns of Academic Staff in a Faculty in the University of Benin, Nigeria. Ife Journal of Science, 15(1): $81-91$ 
Hamed, AT; Kiyoumars, J; Arash, H; Afshin, AK; Amin, T; Seyed, AA (2013). Application of Markov Chain in Forecasting Demand of Trading Company. Interdisciplinary Journal of Contemporary Research in Business, 5(1): 1070 $-1074$

Igboanugo, AC; Onifade, MK (2011).Markov Chain Analysis of Manpower Data of Nigerian University. Journal of Innovative Research in Engineering and Science, 2(2): 107 - 123

Kwon, H; Byung, J; Eui-Jin, L; ByungHoon, Y (2006). Prediction of Human Resource Supply/Demand in Nuclear Industry Using Markov Chain Model and Job Coefficient. Transactions of Korean Nuclear Society Autumn Meeting, Gyeongin, Korea, November $2-3$, 2006

Lindgreen, BW (1993). Statistical Theory $\left(4^{\text {th }}\right.$ edition). Chapman \& Hall, New York

Meng-Chuan, T; Ya-Ring, L; Pi-Heng, C (2014).A Study on Predicting the Turnover of Nursing Staff of Different Education Backgrounds; Using the Absorbing Markov Chain Method. Journal of Quality, 21(6): $499-518$

Nyandwaki, MJ; Kennedy, J (2016). Statistical Modeling of Kenyan Secondary School Students Enrollment : An Application of Markov Chain Model. IOSR Journal of Mathematics, 12(2): 11 $-18$

Osagiede, AA; Ekhosuehi, VU (2006).Markovian Approach to School Enrolment Projection Process. Global Journal of Mathematical Science, 5(1): $1-7$
Parma, D; Raisinghani, S; Makwana, P (2013). Application of Markovian Theory in Manpower Planning: A Case Study. Global Research Analysis, 2(2): 122124.

Rachid, B; Mohamed, T (2013). A Markov Model For Human Resources Supply Forecast Dividing the HR System into Sub-groups. Journal of Service Science and Management, 6: $211-217$

Rahela, AR (2015). Analyzing Manpower Data of Higher Learning Institutions; A Markov Chain Approach. International Journal of Human Resource Studies, 5(3): 38 - 47

Wan-Yin, D; Shou, L (2015).Application of Markov Chain Model in Human Resource Supply Forecasting in Enterprises. International Conference on Computational Science and Engineering (ICCSE, 2015)

Touama, HY (2015). Application of Markovian Models and Transition Probabilities' Matrix to Analyze the Workforce Movement in Jordian Productivity Companies. Indian Journal of Research, 41(6): 215 - 218

Uche, PI; Ezepue, PO (1991).The Markovian Model of academic Staff Flow in Tertiary Institution. Journal of Nigerian Statistical Association, 6 (1): $49-68$ 